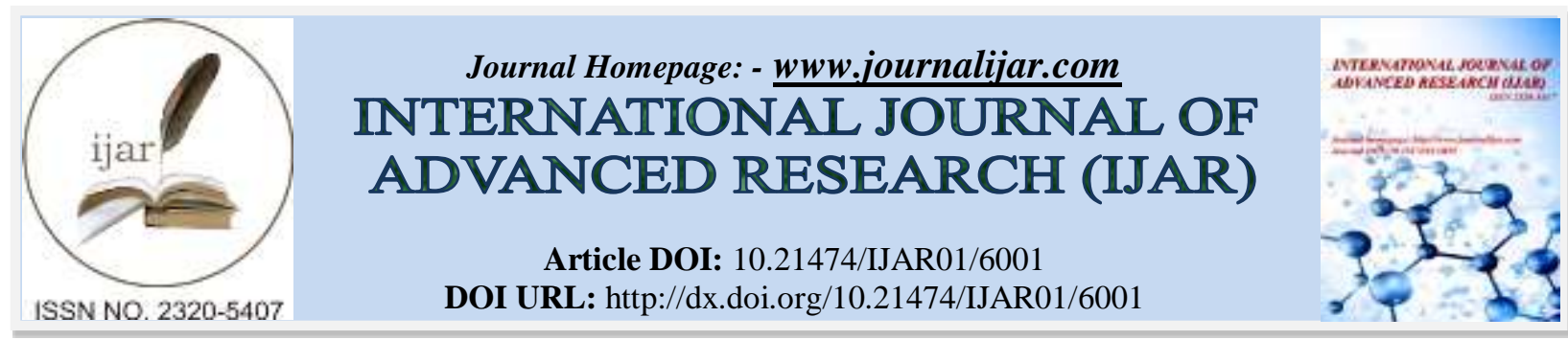

RESEARCH ARTICLE

\title{
MODELING INFLOW PERFORMANCE RELATIONSHIP FOR THREE PHASE FLOW IN BOUNDED RESERVOIRS.
}

\section{Ramadan Emara ${ }^{1,2}$.}

1. Mining and Petroleum Engineering Department, Faculty of Engineering, Al Azhar University.

2. Petroleum and Natural Gas Technology Department, Faculty of Engineering, The British University in Egypt.

\section{Manuscript Info}

Manuscript History

Received: 08 October 2017

Final Accepted: 10 November 2017

Published: December 2017

Key words:-

Three-phase IPR; Inflow performance; oil production.

\begin{abstract}
The efficient operation of producing wells requires reasonable estimates of well performance. This includes reservoir, wells and surface facility monitoring. Therefore, it is important to a petroleum engineer to have suitable methods to design artificial lift equipment, optimum production scheme and forecast production for planning objectives. The essential tool that required to monitor well performance is inflow performance relationship (IPR).

This paper investigates the rate-pressure behavior for three phase flow in oil wells producing through the boundary dominated flow regime. A 300 data point were collected from simulation of six basic sets of fluid property data and relative permeability curves with five different values of water cut $20 \%, 40 \%, 60 \%, 80 \%$ and $90 \%$. Reservoir properties varies as follows: initial pressure ranging from 2100 to 4800 psi; temperature of 160 to $220^{\circ} \mathrm{F}$; oil gravity of 25 to $50^{\circ} \mathrm{API}$; gas gravity of 0.5 to 0.65 ; drainage radius of 526 to $1050 \mathrm{ft}$; height of 25 to $40 \mathrm{ft}$; porosity of $12 \%$ to $24 \%$; permeability of 10 to $350 \mathrm{md}$; irreducible water saturation of $10 \%$ to $55 \%$; critical gas saturation of $5 \%$ to $6 \%$ and residual oil saturation of $5 \%$ to $45 \%$. From simulation outcomes analysis, empirical model of inflow performance relationship for threephase flow was developed based on non-linear regression analysis.

Statistical and graphical analyses were used to evaluate the performance of the developed model. The obtained outcomes include an average relative error (ARE) of 0.76 and coefficient of regression $\left(\mathrm{R}^{2}\right)$ of 0.998 . The proposed model of IPR was compared to other vertical inflow performance relationships available in the previous works. The presented correlation exhibited suitable approximations of well performance over a wide range of operating circumstances.
\end{abstract}

Copy Right, IJAR, 2017,. All rights reserved.

\section{Introduction:-}

Several items are very important to successful reservoir management, of these items, design artificial lift equipment, design stimulation treatments, optimum production scheme determination and forecast production for planning purposes. Each of these items requires reasonable estimates of well deliverability modeling, which joins a reservoir deliverability model with tubular hydraulic calculation. The reservoir deliverability model is a relationship between the fluid inflow and the pressure difference between reservoir and well-bore. Productivity Index (PI) was the first 
relationship of a reservoir deliverability model, and it is a straight-line relationship between the producing rate and the pressure difference. PI can be deduced from the steady-state flow Darcy's ${ }^{1}$ equation of a single incompressible fluid. Based on theoretical calculations, Evinger and Muskat ${ }^{2,3}$ noticed that a curved relationship between pressure for two and three phase flow and flow rate. Vogel $^{4}$ utilized a computer model to simulate various conditions in vertical wells of hypothetical saturated oil reservoirs to create inflow performance curves. He normalized the predicted IPR and introduced the dimensionless form of these relations. The mathematical model, which presented in Vogel work, is simple, give suitable results and gain exceptional approval in the industry. Standing ${ }^{5}$ proceeded the calculation method of Vogel's IPR. He took into consideration the existence of damaged region nearby the well and presented the effective pressure parameter to Vogel equation. This parameter was similar to the pressure at the damaged zone outer boundary, and it was utilized in computation instead of bottomhole flowing pressure. Furthermore, in the calculation of the effective pressure parameter, Standing introduced the flow efficiency factor and it is taken to be equal to the ratio of productivity index of a well without the damaged region to the identical one with the damaged region. Using of Standing method outcomes unbending of the IPR curve as the value of skinfactor is increased. In addition, as the value of skin-factor becomes negative, Standing approach creates physically inadequate outcomes (the oil flow rate decrease at the low values of bottomhole pressure). As later proven by Camacho et al. ${ }^{6}$ and Wiggins ${ }^{7}$ the shape of IPR curve was not affected by the existence of skin-factor. The outcomes achieved by Standing are correlated to the skin-factor as a non-dimensional pressure alteration nearby the wellbore which is linearly rely on the oil flow rate. Actually gas and oil flow rates together out of the near-wellbore damaged region as well as out of the undamaged part of the area around the wellbore. Furthermore, Wiggins ${ }^{7}$ referenced the absence of relation between drainage area shape and IRP curve. Standing ${ }^{8}$ proposed a correlation that presents the connection between geometrical reservoir and fluids properties and Vogel's IPR. Fetkovich ${ }^{9}$ introduced an appropriate approach to calculate the IPR for three possible production schemes using experimental data of multirate tests accomplished in forty producing oil wells of six different fields. He displayed that, once the gas saturation is greater than the critical gas saturation, the typical pressure-rate equation of gas wells may also be used for oil wells. The IPR model that introduced in Fetkovich study requires more than one stabilized flow-rate point. However, this model also gain suitable acceptance in the industry.Brown ${ }^{10}$ developed an approach suggested by Petrobras for defining the inflow performance of three-phase flow. He used the constant PI for the production of water and joined it to the IPR which developed by Vogel to attain a composite inflow performance relationship. Wiggins ${ }^{11}$ investigated the solution gas drive reservoir performance using a computer model to develop inflow performance relationships for vertical wells. He utilized four sets of fluid properties data and various relative permeability curves and assumed that, the production of water to become from porous media homogeneous water saturation, i.e., interstitial water, and initial reservoir pressure is taken to be equal to bubble point pressure. The presented models in Wiggins study calculates IPR curves for three-phase flow; oil, gas and water. In comparison with Vogel work, the generated relations developed by Wiggins are similar and are expressed to evaluate the parabolic coefficient of Vogel equation depending on water cut. As well, the proposed equations require only one stabilized flow test in the well to estimate the oil and water maximum production rates. The equation developed by Klins \& Clark ${ }^{12}$ is similar to the one generated by Vogel. And, in their seeking to improve the results exactness, the constant parabolic exponent (2) in Vogel correlation is transformed to a new exponent "d". This exponent function of the bubble point pressure and its relation to the reservoir pressure. Furthermore, the parabolic constants were set to values a little dissimilar from the ones assessed by Vogel. Mohamed Elias et al. ${ }^{13}$ built a single well 3D radial reservoir model using MORE (Schlumberger computer tool) reservoir simulator and investigated the shape and in turn the relationship between the oil mobility function and the average reservoir pressure. They presented an inflow performance relationship based on the resulted oil mobility- pressure profile. This IPR is primarily taken as a function of the relationship between the average reservoir pressure and the oil mobility. They used forty-seven field cases (published cases) to develop this equation. Mars Khasanov et al. ${ }^{14}$ presented self-consistent approach to build inflow performance relationship (IPR) for vertical oil well operated under solution gas drive. The equation is suggested based on the analytical derivation using pseudo-pressure function approach and in the form of power law. In case of existence of a transition zone where mobility of oil decrease for the pressure values near the bubble-point pressure, they introduced a correction to modify IPR curve behaviour. Fuad Qasem et al. ${ }^{15}$ investigated the reservoir heterogeneity effects on IPR curves for well producing from multi-layers solution gas drive reservoirs. They used stochastic simulation algorithm known as simulated annealing to produce different permeability realizations between the stacked layers. An advanced black oil numerical simulator IMAX has been used in their investigation. They presented inflow performance relationships similar to Vogel's IPR for two and multi-layers reservoirs. In two layer reservoir, the parabolic coefficient of Vogel equation is taken to be function of permeability ratio and reservoir pressure. In multi-layer reservoir parabolic coefficient is taken to be function of correlation length and DykstraParson coefficient. For the present study, the analytical IPR can be developed to a specific reservoir and its working conditions, but it is requires information of reservoir fluid properties and relative permeability curves and how they 
conduct with pressure. When such data are accessible for the concerned reservoir, come along with the average pressure of the reservoir and water saturation. With this data, one can introduce the essential mobility function values from the present pressure of the reservoir to near-zero flowing pressure. Unfortunately, always we do not have dependable relative permeability or fluid property data. In such situation, the analytical IPR is only of academic purpose. To overcome this issue, three-phase IPR like to Vogel's was presented here. The resulting IPR correlation is based on non-linear regression analysis of simulation outcomes covering a wide range of relative permeability curves, fluid property data and water saturations.

\section{Methodology:-}

To develop three-phase inflow performance relationship, preliminary preparation of data should be made. A single well 3D radial reservoir model using Eclipse100 (Schlumberger computer tool) reservoir simulator was built.

The procedures to obtain the data are limited by the following assumptions: 1) all simulation cases start at the bubble point pressure; 2) no free gas phase is existent at the initial time; 3) a mobile water phase is existent ; 4) Darcy's law applies for multiphase flow; 5) isothermal conditions present; 6) no reaction between reservoir rock and reservoir fluids; 7) no gas solubility presents in the water; 8) effects of gravity are negligible; and 9) the well a fully penetrating wellbore; and 10) the reservoir is completely bounded.

The model was for a vertical well in a cylindrical geometry $(\mathrm{r}, \theta, \mathrm{z})$. The numbers of layers in the reservoir are: fifty (50) layers in radial direction (r), one (1) layer in the angular direction $(\theta)$, and one (1) layer in the vertical direction (z). The single producing vertical well was completed in the center of this layer. The values of geometric reservoir properties were representative of unconsolidated sands. The exponential function was used to distribute the grids in the radial direction to consider the pressure and saturation changes expected to happen on the cells closer to the well-bore than to the external radial layers. Black oil approach is more generally practical to model phase behaviour of solution gas drive reservoir; thus it is adapted in this work.

Viscosities and gas formation volume factors of oil and gas are pressure dependent properties. For IPR curves generation, variation of these properties with pressure must be known. The best way to obtain the pressure and fluid properties relationship is to use pressure-volume-temperature (PVT) tests data. The absence of these data lead the researcher to use empirical correlations that predict this relationship. PETREL program (Schlumberger computer tool) was used to generate the fluid properties data and relative permeability curves using the data described in Table 1 .

Table 1:- Reservoir Properties

\begin{tabular}{|c|c|c|c|c|c|c|c|}
\hline Property & $\begin{array}{l}\text { Case } \\
1 \\
\end{array}$ & $\begin{array}{l}\text { Case } \\
2 \\
\end{array}$ & $\begin{array}{l}\text { Case } \\
3 \\
\end{array}$ & $\begin{array}{l}\text { Case } \\
4 \\
\end{array}$ & $\begin{array}{l}\text { Case } \\
5\end{array}$ & $\begin{array}{l}\text { Case } \\
6 \\
\end{array}$ & $\begin{array}{l}\text { Test } \\
\text { Case }\end{array}$ \\
\hline Initial pressure, psi & 2100 & 2600 & 3100 & 3600 & 4100 & 4800 & 3450 \\
\hline Temperature, ${ }^{\circ} \mathrm{F}$ & 160 & 170 & 180 & 190 & 200 & 220 & 185 \\
\hline Oil Gravity, API & 25 & 30 & 35 & 40 & 45 & 50 & 38 \\
\hline Gas Gravity, fraction & 0.65 & 0.65 & 0.65 & 0.65 & 0.55 & 0.5 & 0.6 \\
\hline Drainage radius, $\mathrm{ft}$ & 526 & 1050 & 526 & 1050 & 750 & 1050 & 750 \\
\hline Wellbore Radius, $\mathrm{ft}$ & 0.328 & 0.328 & 0.328 & 0.328 & 0.328 & 0.328 & 0.328 \\
\hline Height, ft & 25 & 30 & 40 & 25 & 25 & 40 & 20 \\
\hline Porosity, fraction & 0.24 & 0.24 & 0.16 & 0.2 & 0.18 & 0.12 & 0.18 \\
\hline Permeability, md & 350 & 100 & 10 & 150 & 50 & 20 & 50 \\
\hline Irreducible Water Saturation, fraction & 0.55 & 0.3 & 0.1 & 0.2 & 0.2 & 0.2 & 0.25 \\
\hline Critical Gas Saturation, fraction & 0.05 & 0.05 & 0.05 & 0.05 & 0.05 & 0.06 & 0.05 \\
\hline Residual Oil Saturation, fraction & 0.05 & 0.1 & 0.45 & 0.35 & 0.05 & 0.1 & 0.35 \\
\hline
\end{tabular}

Table 1 illustrates the ranges of reservoir properties data utilized in the development of the proposed three-phase IPR model. As shown from this Table, Reservoir properties varies as follows: initial pressure of 2100 to 4800 psi; temperature of 160 to $220^{\circ} \mathrm{F}$; oil gravity of 25 to $50^{\circ} \mathrm{API}$; gas gravity of 0.5 to 0.65 ; drainage radius of 526 to 1050 $\mathrm{ft}$; height of 25 to $40 \mathrm{ft}$; porosity of $12 \%$ to $24 \%$; permeability of 10 to $350 \mathrm{md}$; irreducible water saturation of $10 \%$ to $55 \%$; critical gas saturation of $5 \%$ to $6 \%$ and residual oil saturation of $5 \%$ to $45 \%$. Data required for IPR calculations are bottom-hole pressure and oil and water production rates. To obtain such data, the computer tool (Eclipse) was used to simulate six basic sets of fluid property data and relative permeability curves with five 
different values of water cut $(20 \%, 40 \%, 60 \%, 80 \%$ and $90 \%)$. All simulation runs were generated under the constraint of a constant bottom-hole pressure. At each simulation run, a small time step was applied to model the initial stages of well production. At each water cut, every data set was used to carry out draw-down tests through setting bottom-hole pressures equal to $0.95,0.85,0.75,0.65,0.55,0.45,0.35,0.25$, and 0.15 of initial reservoir pressure and the last value of bottom-hole pressure was taken to be equal to 14.7 psia. When pseudo steady state reached, the oil and water production rates for each point of the tests were determined. The maximum oil and water production rates were evaluated for each run at a minimum bottom-hole flowing pressure of 14.7 psia. A total of 300 data points were collected from 30 theoretical reservoirs in 300 simulator runs. Fig. 1 show a typical liquid inflow performance curves for all simulation cases.

Case 1

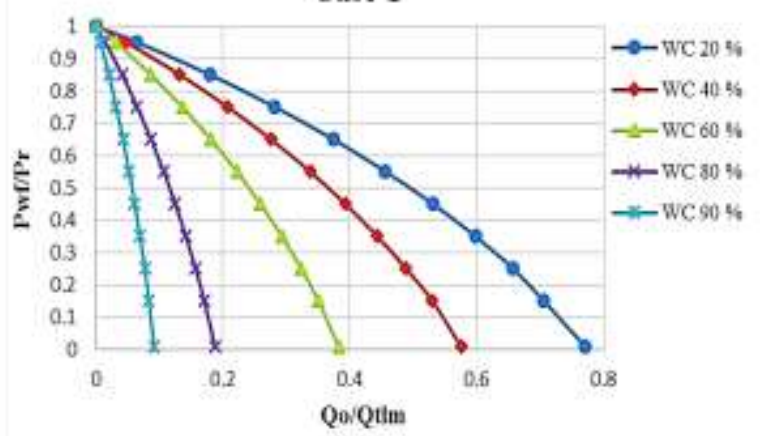

Case 3

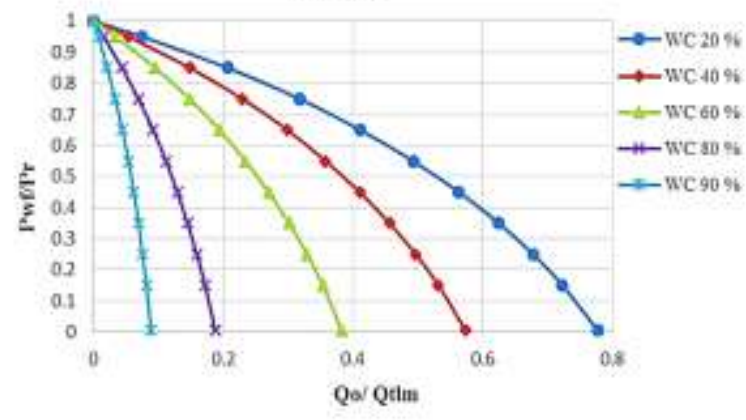

Case 5

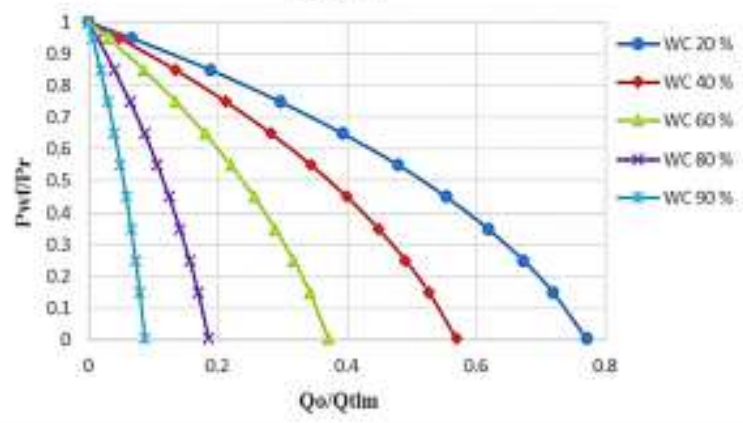

Case 2

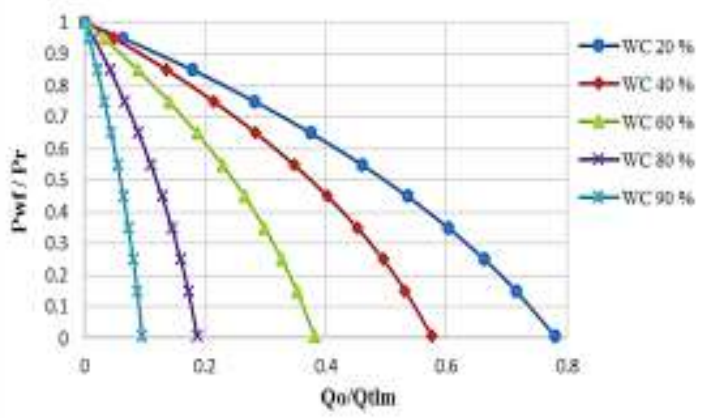

Case 4

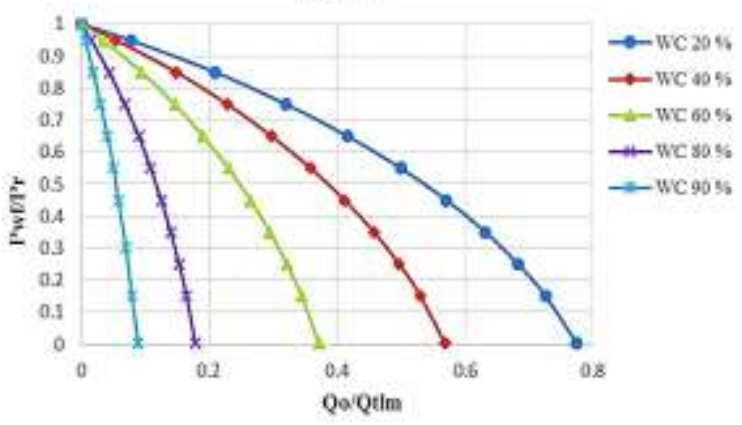

Case 6

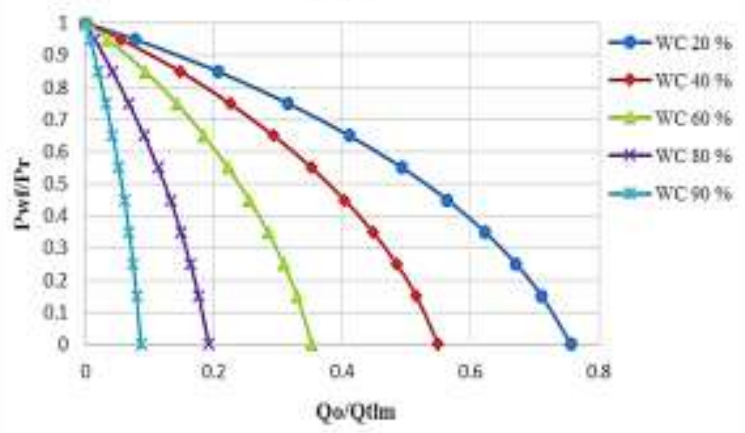

Fig. 1:- Oil IPR curves for all simulation results

The resulting IPR curves are similar to Vogel curves in concave shape feature. To develop a three-phase IPR model, the results of all simulation runs are grouped based on the value of water cut, and it is shown on Fig. 2. 


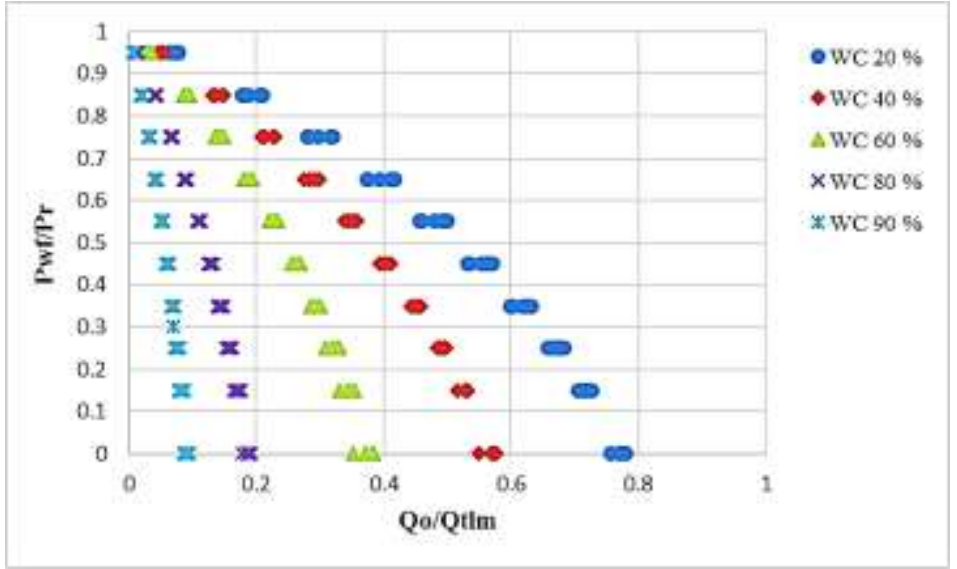

Fig. 2:- Results water cut grouped basis.

Nonlinear regression analysis implemented on these results, show that the equation in polynomial form of degree two is selected. Generally the equation can be written as follows:

$\frac{q_{o}}{q_{t l m}}=c_{1}+c_{2} \frac{p_{w f}}{p_{r}}+c_{3}\left(\frac{p_{w f}}{p_{r}}\right)^{2}$

Where:

$c_{1}=2.8843857 * 10^{-6} y^{2}-0.0098504 * y+0.9531957$

$c_{2}=1.5783718 * 10^{-5} y^{2}+0.0005387 * y-0.2172572$

$c_{3}=-2.231337 * 10^{-5} y^{2}+0.0096918 * y-0.7394986$

Where:

$y=\frac{w c}{x_{1} \exp \left(\frac{p_{w f}}{p_{r}}\right) x_{2}}$

Where:

$x_{1}=1.4687993-0.1031508 \operatorname{Ln}(\mathrm{wc})$

$x_{2}=-0.416555+0.0986312 \operatorname{Ln}(\mathrm{wc})$

$w c=\left(\frac{q_{w}}{q_{w}+q_{o}}\right) * 100$

\section{Correlation Validation:-}

In order to validate the accuracy of the derived correlation, statistical and graphical analyses have been used to evaluate its performance. Statistical indicators are presented in the appendix. The obtained outcomes include an average relative error (ARE) of 0.76 and coefficient of regression $\left(\mathrm{R}^{2}\right)$ of 0.998 . Also, from the crossplot of dimensionless flow rate as shown in Fig 3, an excellent match between the predicted and the simulated data. 


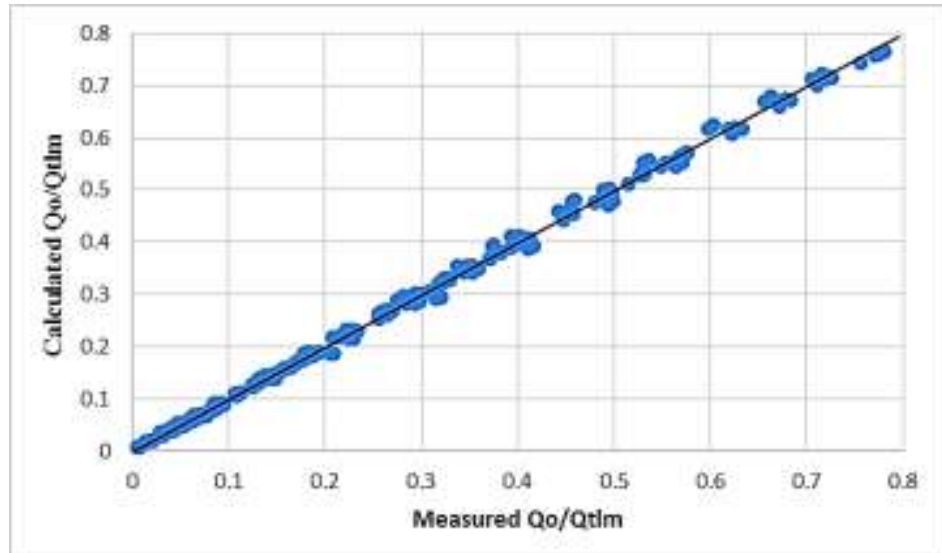

Fig. 3:- Crossplot of dimensionless flow rate.

\section{Calculation Procedure:-}

The calculation procedure for the proposed model of three-phase IPR is as follows:

1. Obtain the reservoir pressure, the bottom-hole flowing pressure and oil and water flow rates from the drawdown test data.

2. Using equation (8) to calculate the water cut.

3. Calculate the y coefficient using equation (5) to calculate the $c_{n}$ coefficients of equation (1).

4. Calculate the maximum total liquid flow rate, using equation (1) with the test data

5. Using the maximum total liquid flow rate from step 4, the oil flow rate at the corresponding bottom-hole flowing pressure can be calculated from equation (1)

6. Using equation (5) to calculate water cut by predetermined y from step 3 at the corresponding bottom-hole flowing pressure. Use the following equation to calculate the water flow rate.

$$
q_{w}=\left(\frac{w c}{100-w c}\right) * q_{o}
$$

\section{Results and Discussion:-}

The approach and the proposed IPR model introduced in this work for multiphase flow were developed from study of three-phase flow in homogeneous, bounded reservoirs where there is no fluids that come from external source into the reservoir, and apply to the dominated boundary flow regime. For verifying the proposed three-phase inflow performance relationship, the last column of Table 1 illustrates a simulation case that was used for comparison purpose. This information was not used in the proposed IPR model development. Table 2 illustrates the simulated drawdown test data. Fig 4 shows an excellent match between the predicted IPRs and the simulated IPRs.

Table 2:- Drawdown test data 1

\begin{tabular}{|l|l|}
\hline Reservoir Pressure, psi & 3450 \\
\hline Bottom-hole Flowing Pressure, psi & 1552.5 \\
\hline Oil Flow Rate, bbl/d & 1125.09 \\
\hline Water Flow Rate, bbl/d & 924.184 \\
\hline Water Cut, percent & 45.089 \\
\hline
\end{tabular}




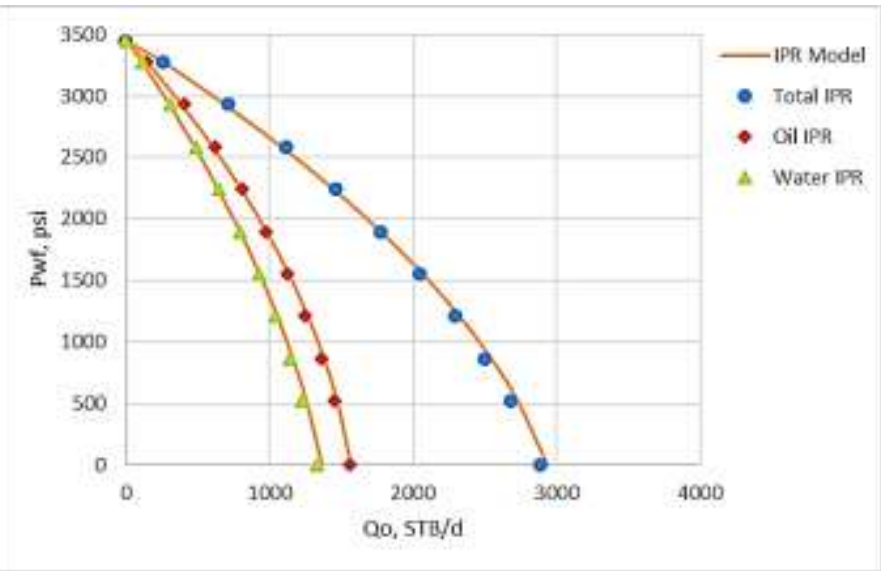

Fig. 4:- Comparison of simulator results versus the proposed IPR model.

From the literature, it has been found that only Brown and Wiggins have published three-phase inflow performance relationships. In order to evaluate the presented IPR model reliability, the IPR was compared with the methods of Brown and Wiggins for three-phase IPR. Brown's approach was projected by Petrobras and is founded on evolving a composite IPR curve. The composite curve is developed by utilizing IPR for the oil phase of Vogel and joining it with water phase straight-line PI. Method of Wiggins is based on linear regression analysis of simulation outcomes of four groups of data. Where, each group of date was utilized to produce oil and water IPRs from irreducible water saturation to residual oil saturation. In this paper the simulation outcomes were generated from irreducible water saturation to reach pseudo steady state for each set of data. And, the developed model is based on non-linear regression analysis of the simulation outcomes. The data published by Wiggins ${ }^{11}$ were used to compare the reliability of the presented IPR model with the three-phase IPR approaches of Brown and Wiggins. These data were not used in the development of the proposed model and illustrated in Table 3. It was felt that this group of data would provide an unbiased significance of the reliability of the developed IPR model.

Table 3:- Drawdown test data 2

\begin{tabular}{|l|l|l|l|l|}
\hline \multirow{2}{*}{ Test Data } & Pwf, psi & Pr, psi & qo, bbl/d & qw, bbl/d \\
\cline { 2 - 5 } & 1155 & 2100 & 176.31 & 50.164 \\
\hline
\end{tabular}

Tables 4 illustrates the outcomes of this analysis and also these outcomes are presented in Fig 5 and 6. In Fig. 5 Wiggin method produce close value of the maximum oil flow rate. While, Brown method underpredicts this value and the proposed model comes in the middle. In Fig. 6 Wiggin and the proposed model produce a value of the maximum water flow rate slightly different from the simulation outcome. While, Brown method underpredicts this value. From this analysis all three approaches produce like estimates of producing rates, denoting the proposed three-phase IPR model gives suitable results. This analysis indicates that any of the three approaches seem suitable for utilize through boundary-dominated flow. The proposed IPR model is recommended for use in applying to field data.

Table 4:- Comparison of oil and water proposed IPR to Wiggin and Brown methods

\begin{tabular}{|c|c|c|c|c|c|c|c|c|}
\hline $\mathrm{P}_{\mathrm{Wf}}$ & $\begin{array}{l}\text { Simulator } \\
\mathrm{q}_{\mathrm{o}}, \mathrm{bbl} / \mathrm{d}\end{array}$ & $\begin{array}{l}\text { Wiggins } \\
\mathrm{q}_{\mathrm{o}}, \mathrm{bbl} / \mathrm{d}\end{array}$ & $\begin{array}{l}\text { Brown } \mathrm{q}_{\mathrm{o}} \text {, } \\
\mathrm{bbl} / \mathrm{d}\end{array}$ & $\begin{array}{l}\text { Proposed } \\
\text { model } \\
\mathrm{q}_{\mathrm{o}}, \mathrm{bbl} / \mathrm{d} \\
\end{array}$ & $\begin{array}{l}\text { Simulator } \\
\mathrm{q}_{\mathrm{w}}, \mathrm{bbl} / \mathrm{d}\end{array}$ & $\begin{array}{l}\text { Wiggins } \\
\mathrm{q}_{\mathrm{w}}, \text { bbl/d }\end{array}$ & $\begin{array}{l}\text { Brown } \mathrm{q}_{\mathrm{w}} \text {, } \\
\mathrm{bbl} / \mathrm{d}\end{array}$ & $\begin{array}{l}\text { Proposed } \\
\text { model } \mathrm{q}_{\mathrm{w}}, \\
\mathrm{bbl} / \mathrm{d}\end{array}$ \\
\hline 1995 & 23.064 & 22.52 & 22.82 & 24.56 & 5.908 & 5.51 & 6.47 & 6.53 \\
\hline 1785 & 66.098 & 65.48 & 65.94 & 68.61 & 17.535 & 17.47 & 18.71 & 18.54 \\
\hline 1575 & 105.875 & 105.45 & 105.54 & 108.58 & 28.849 & 28.89 & 29.94 & 29.85 \\
\hline 1365 & 142.657 & 142.44 & 141.38 & 144.48 & 39.729 & 39.75 & 40.11 & 40.41 \\
\hline 1155 & 176.31 & 176.44 & 173.2 & 176.31 & 50.164 & 50.06 & 49.14 & 50.16 \\
\hline 945 & 207.013 & 207.46 & 200.71 & 204.07 & 60.014 & 59.81 & 56.94 & 59.07 \\
\hline 735 & 234.453 & 235.5 & 223.59 & 227.76 & 69.18 & 69.02 & 63.43 & 67.08 \\
\hline 525 & 259.002 & 260.56 & 241.46 & 247.37 & 77.459 & 77.67 & 68.5 & 74.13 \\
\hline 315 & 279.344 & 282.62 & 253.85 & 262.92 & 84.644 & 85.77 & 72.03 & 80.17 \\
\hline 0 & 301.77 & 310.13 & 264.46 & 278.60 & 92.672 & 96.89 & 75.03 & 87.21 \\
\hline
\end{tabular}




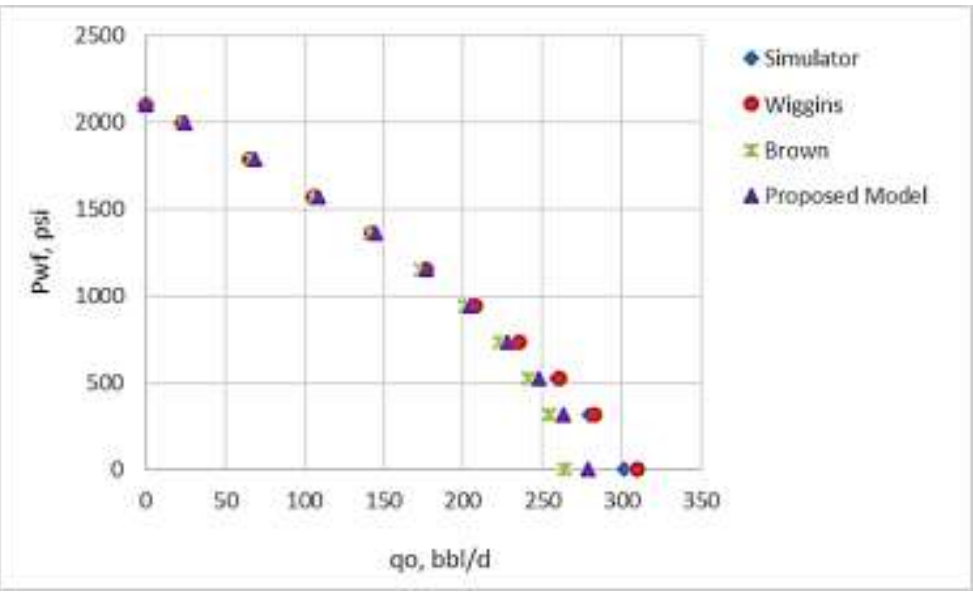

Fig. 5:- Comparison of Proposed Oil IPR versus other Methods using published data.

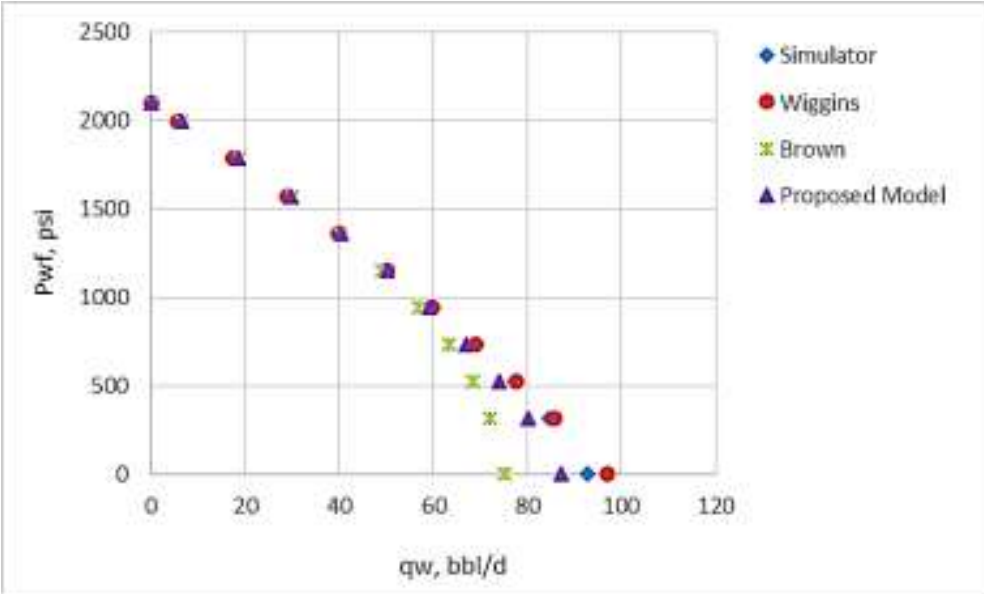

Fig. 6:- Comparison of Proposed Water IPR versus other Methods using published data.

\section{Conclusion:-}

Based on this research the following conclusions are presented.

1. Based on computer simulation outcomes, empirical inflow performance relationship has been presented for three-phase flow in bounded reservoirs.

2. Outcomes of statistical analysis of the proposed IPR model include an average relative error (ARE) of 0.76 and coefficient of regression $\left(\mathrm{R}^{2}\right)$ of 0.998 .

3. The proposed three-phase IPR model is suitable for use over a wide range of reservoir properties.

4. The presented IPR model require one drawdown test which includes the average reservoir pressure, bottom-hole flowing pressure and oil and water production rates to obtain the IPR curve.

5. The proposed IPR model has been evaluated using data presented by Wiggins and by comparison to the threephase inflow performance relationships methods of Brown and Wiggins, the presented IPR model yielded similar results as these two methods.

\section{Nomenclature:-}

$\begin{array}{ll}\mathrm{c}_{1}, \mathrm{c}_{2}, \mathrm{c}_{3} & \text { regression coefficients } \\ \mathrm{P}_{\mathrm{r}} & \text { average reservoir pressure, psi } \\ \mathrm{P}_{\mathrm{wf}} & \text { bottom-hole flowing pressure, psi } \\ \mathrm{q}_{\mathrm{o}} & \text { oil production rate, bbl/d } \\ \mathrm{q}_{\mathrm{tlm}} & \text { maximum total liquid production rate, bbl/d } \\ \mathrm{q}_{\mathrm{w}} & \text { water production rate, bbl/d } \\ \mathrm{x}_{1}, \mathrm{x}_{2}, \mathrm{y} & \text { regression coefficients } \\ \mathrm{wc} & \text { water cut, percent }\end{array}$




\section{Appendix A.}

\section{Statistical Error Analysis}

The following three statistical parameters were used in this study to evaluate the accuracy of the correlations.

1- Average percent relative error (ARE)

Where

$$
E_{r}=\frac{1}{n_{d}} \sum_{1}^{n_{d}} E_{i}
$$

2- Coefficient of correlation

$$
E_{i}=\left(\frac{x_{\text {measured }}-x_{\text {estimated }}}{x_{\text {measured }}}\right)_{i} * 100\left(i=1,2, \ldots n_{d}\right)
$$

$$
\mathrm{r}^{2}=1-\sum_{1}^{\mathrm{n}_{\mathrm{d}}}\left(\mathrm{x}_{\text {measured }}-\mathrm{x}_{\text {estimated }}\right)^{2} / \sum_{1}^{\mathrm{n}_{\mathrm{d}}}\left(\mathrm{x}_{\text {measured }}-\mathrm{x}_{\text {avarage }}\right)^{2}
$$

The lower the value of $E_{\mathrm{r}}$ the more equally distributed are the errors between positive and negative values. The lower value of $\mathrm{E}_{\mathrm{a}}$ the better the correlation. The correlation coefficient describes the range of connection between two variables namely experimental and estimated values obtained from the correlation. The value of $\mathrm{r}^{2}$ varies from 1 to +1 . As the value of correlation coefficient approaches +1 , it means there is a strong positive relationship between these two variables.

\section{References :-}

1. Ahmed, T. and McKinney, P.: "Advanced Reservoir Engineering", published by Gulf Professional Publishing, Oxford, 2005.

2. Evinger, H.H. and Muskat, M.: "Calculation of Theoretical Productivity Factors", Trans., AIME (1942) 146, 126-139.

3. Evinger, H.H. and Muskat, M.: "Calculation of Productivity Factors for Oil-gas-water Systems in the Steady State", Trans., AIME (1942) 146, 194-203.

4. Vogel, J.V.: "Inflow Performance Relationships for Solution-Gas Drive Wells", JPT (Jan. 1968) 83-92.

5. Standing M.B. : "Inflow Performance Relationships for Damaged Wells Producing by Solution Gas Drive Reservoirs", J. Pet. Tech. (November 1970), p. 1399-1400.

6. Camacho V. : "Raghavan R. Inflow Performance Relantionships for Solution-Gas-Drive Reservoirs", J. Pet. Tech. (May1989), p. 541-550.

7. Wiggins M. : "Analytical Development of Vogel-Type Inflow Performance Relationships", SPE paper 23580, 1996.

8. Standing M.B. : "Concerning the Calculation of Inflow Performance of Wells Producing from Solution Gas Drive Reservoirs", SPE paper 3332, 1971.

9. Fetkovich, M.J.: "The Isochronal Testing of Oil Wells", paper SPE 4529 presented at the 1973 SPE Annual Meeting, Las Vegas, NV, Sept. 30 - Oct.

10. Brown, KE.: "The Technology of Artificial Lift Methods", PennWell Publishing Co., Tulsa, OK (1984) 4, 1835.

11. Wiggins, M.L. : "Generalized Inflow Performance Relationships for Three-phase Flow", paper SPE 25458 presented at the 1993 Production Operations Symposium, Oklahoma, USA, Mar. 21-23

12. Klins M.A. and Clark J.W. : "An Improved Method to Predict Future IPR Curves", paper SPE 20724 Reservoir Engineering, November 1993

13. Mohamed Elias, H. Ahmed El-Banbi, K.A. Fattah, and El-Sayed Ahmed Mohamed El-Tayeb, Cairo University. : "New Inflow Performance Relationship for Solution-Gas Drive Oil Reservoirs", paper SPE 124041 presented at Annual Technical Conference and Exhibition held in New Orleans, Louisiana, USA, 4-7 October 2009.

14. Mars Khasanov, Rinat Khabibullin, Timur Musabirov. : "Self Consistent Approach to Construct Inflow Performance Relationship for Oil Well", paper SPE 160782 presented at the SPE Russian Oil \& Gas Exploration \& Production Technical Conference and Exhibition held in Moscow, Russia, 16-18 October 2012.

15. Fuad Qasem, Adel Malallah, Ibrahim Sami, and Mohamed Irfan.:" Modelling Inflow Performance Realtionships for Wells Producing from Multi-Layer Solution Gas Drive Reservoir”, paper SPE 149858 presented at North Africa Technical Conference and Exhibition held in Cairo, Egypt, 20-22 February 2012. 